\title{
Prevalence of Radiographic Anomalies and Abnormalities on Panoramic Films in the Pakistani Population
}

\author{
Samra Asif ${ }^{1}$
}

Hassaan Bin Babar ${ }^{2}$

Fatima Kamal ${ }^{3}$

Kanwal Sohail ${ }^{4}$

Amber Kiyani ${ }^{5}$

BDS, M.Phil

OBJECTIVES: Orthopantomogram (OPG) is a dental radiograph that captures the maxillofacial region in a single image for quick assessment of the dental arches and their surrounding structures. It can be used for treatment planning and analysis of jaw-related pathologies. Prior studies have demonstrated geographical variations in radiographic anomalies and pathologies, our purpose was to establish baseline statistics for the Pakistani population, so the Pakistani dentists are able to distinguish between anomalies and pathologies and provide appropriate care when needed.

METHODOLOGY: A cross-sectional study design was used to analyze de-identified 2411 OPGs taken for routine dental care at the dental clinics of Riphah International University. These were broadly classified according to site. Data was documented on SPSS version 22 and presented as frequencies.

RESULTS: From a total of 2,411 OPGs, 2326 met the inclusion criteria. The mean age of the patients was $29.06 \pm 17.99$ years. Our findings included pneumatization of the maxillary sinus in $9.8 \%$, pathological findings in the sinus in $3.9 \%$, deflected nasal septum in $7.5 \%$, alveolar bone loss in $32.7 \%$, elongated styloid process in $12.1 \%$, pathological finding associated with maxillary bone in $1.4 \%$ and mandibular bone in $2.1 \%$.

CONCLUSIONS: Our results were somewhat unique when compared with studies from other geographical locations. We established baseline statistics about the common anomalies and abnormalities noted in dental radiographs for the Pakistani population.

KEY WORDS: Orthopantomogram, anomalies, mandible, maxilla

HOW TO CITE: Asif S, Babar HB, Kamal F, Sohail K, Kiyani A. Prevalence of radiographic anomalies and abnormalities on panoramic films in the Pakistani population. J Pak Dent Assoc 2021;30(2):124-129.

DOI: https://doi.org/10.25301/JPDA.302.124

Received: 30 June 2020, Accepted: 01 January 2021

\section{INTRODUCTION}

$\mathrm{P}$ anoramic radiography or orthopantomogram (OPG) is a dental radiograph that captures the maxillofacial region in a single image. This radiograph allows a quick assessment of the dental arches for tooth-related problems, fractures, cysts and tumors. ${ }^{1}$ The anatomical landmarks clearly visible in the OPG include the nasal bone, maxillary sinus, maxillary bone, mandible, styloid process, temporomandibular joint, alveolar bone, and cervical vertebrae. $^{2}$

1. Final year student, Riphah International University, Islamabad.

2. Final year student, Riphah International University, Islamabad.

3. Final year student, Riphah International University, Islamabad.

4. Demonstrator, Department of Oral Medicine, Riphah International University, Islamabad.

5. Assistant Professor, Department of Oral Diagnosis and Medicine, Riphah International University, Islamabad.

Corresponding author: “Dr. Amber Kiyani”’ < akiyani@gmail.com >
Studies have shown that variations in the anatomical landmarks exist between populations. For example, the length of styloid process can from range between 20 to 32 $\mathrm{mm}$, variations are noted in different races, gender, age groups, and even within the same individual. Similarly, changes in the shape of coronoid and condylar processes of the mandible, and location of inferior alveolar canal and mental foramen have also been documented. ${ }^{3-11}$ The importance of these variations is predicated on the fact that although they anatomically differ from the perceived traditional presentation, they usually do not require therapeutic intervention. They can, however, present diagnostic dilemma for the untrained eye or may cause symptoms. The asymptomatic nature of these findings remains the reason they are undetected and revealed incidentally on radiographs taken for other ailments. ${ }^{5,11}$ Although literature is available from other countries, documentation of radiographic changes 
in the Pakistani population is insufficient.

The purpose of this investigation was to determine the prevalence of anomalies and pathologies on OPGs taken for routine dental care at a dental teaching hospital. Our results will be important in establishing baseline statistics for the Pakistani population and familiarize Pakistani dentists with common radiographic changes. They will also be able to identify pathological entities that require medical attention.

\section{METHODOLOGY}

This study was approved by the Ethical Review Board at Riphah International University, Islamic International Dental College (IIDC/IRC/2020/06/04).

A retrospective, cross-sectional study was designed to evaluate OPGs. OPGs taken for routine dental care from February 2018 to April 2019 at Islamic International Dental Hospital were conveniently sampled. Visually clear images distinctly exhibiting all required anatomical landmarks were included for evaluation. All blurred, over exposed, underexposed images were excluded from the sample. Patient identifiers were removed before dissemination of information.

The landmarks were categorized under alveolar bone, mandible, maxilla, styloid process, maxillary sinus, nasal bones, inferior alveolar canal and condyle. Record of all radio-opaque and radiolucent changes was made. Alveolar bone loss was noted. Any significant change in shape and size of the structures was also highlighted. The position and displacement of the condyle, if any, were recorded. Elongation of styloid process and maxillary sinus lining was also noted.

The entire data set was analyzed by three dental students independently and verified by a radiologist. All anomalies and abnormalities identified on OPGs were recorded and analyzed using Statistical Packages for Social Sciences version 22. Data analysis was done by calculating frequencies and percentages for all anomalous and pathologic findings. These were represented in the form of tables, charts or graphs.

\section{RESULTS}

Out of total 2,411 radiographs taken, 2,326 records satisfied the inclusion criteria. Of these 955 subjects were male $(41.1 \%)$ and 1371 were female (58.9\%). Patients were aged between 3-93 years with mean age of $29.06 \pm 17.79$ years.

\section{MAXILLARY SINUS}

Nine hundred and thirteen (36\%) OPGs were found to be normal with no anomalous or pathologic findings. Abnormal findings were noted in 1,498 (64\%) from 2,326 radiographs. These included:

- Excess pneumatization of the maxillary sinus (MSP) was seen in $228(9.8 \%)$ bilaterally. Unilaterally the MSP on the left side only was seen in 59(2.5\%) and on theright side in 25 OPGs (1.1\%).

- Radiopacities were noted in 64 (2.7\%) OPGs, this included $38(1.6 \%)$ in the left sinus and 29 on the right $(1.2 \%)$.

- Corticated radiolucencies and radiopacities were seen in $29(1.2 \%)$ OPGs, $17(0.7 \%)$ on the left and 15 $(0.6 \%)$ on the right.

- Fractures of the sinus were seen on 2 radiographs.

- For a total of $6(0.03 \%)$ patients, the boundary of the sinuses was not intact.

Figure 1: Distribution of maxillary sinus anomalies and abnormalities

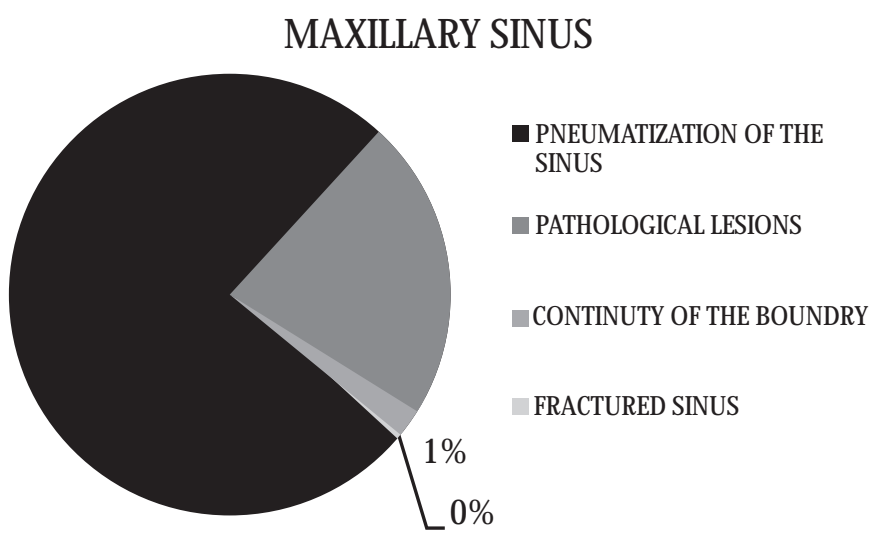

\section{NASAL BONE}

Two thousand one hundred and ten OPGs (86\%) showed no significant changes in the nasal bone. The remaining 216 (8.3\%) OPGs showed:

- Deflected nasal septum in 198 (7.5\%) OPGs.

- Radiolucent lesions on $8(0.3 \%)$ radiographs.

- Radio-opaque lesions in 7 (0.3\%) cases.

- Three $(0.1 \%)$ radiographs showed discontinuity of the nasal septum, this feature is indicative of fracture of nasal bone.

\section{ALVEOLAR BONE LEVEL}

We noted normal alveolar bone levels in 1,462 (55.7\%) OPGs, $6(0.3 \%)$ patients were edentulous and the remaining 943 (36\%) exhibited:

- 798 (30.4\%) OPGs showed generalized alveolar bone loss. 
- $60(2.3 \%)$ showed localized alveolar bone loss.

\section{CONDYLE OF MANDIBLE}

From 4,648 condyles evaluated, $916(19.7 \%)$ appeared to be anteriorly displaced while $3,636(78.2 \%)$ were concentric.

\section{STYLOID PROCESS}

The styloid process was evaluated on 2,326 OPGs. In $282(12.1 \%)$ elongation of the styloid process was seen. The patterns of elongation were as follows:

- $21(0.8 \%)$ showed unilateral elongation.

- 261 (9.9\%) showed bilateral elongation.

Figure 2: OPG showing elongated styloid process

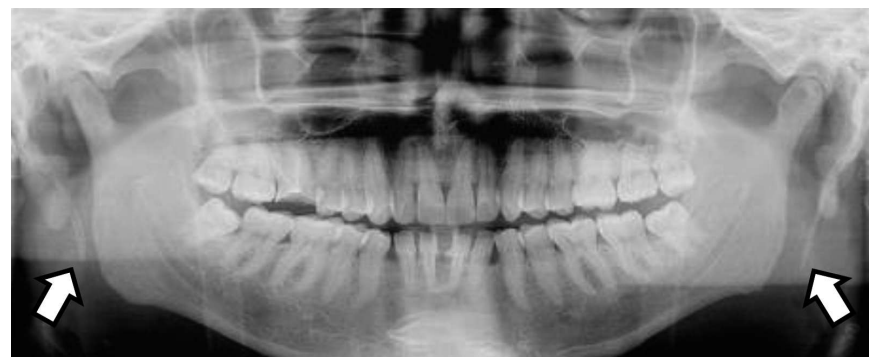

\section{INFERIOR ALVEOLAR CANAL}

OPGs from 2381 (99\%) patients showed no pathological changes in association with the inferior alveolar canal. The remaining 30 (1\%) OPGs showed:

- Radiolucencies in $5(0.2 \%)$ cases.

- Radiopacities in 5(0.2\%) OPGs

- $20(0.9 \%)$ OPGs with dilated canal.

\section{JAWS (MAXILLA AND MANDIBLE)}

\section{Radiopacities:}

OPGs revealed presence of well-defined, roughly spherical-shaped, radiopaque lesions in $94(4.04 \%)$ cases.

There was 38 (1.4\%) lesions present in maxilla. These included:

- $19(0.72 \%)$ associated with the apex of the roots of tooth. Nine were situated in the anterior region and 10 in posterior region.

- $19(0.72 \%)$ were in other locations (3 in anterior region 16 in posterior region).

There were $56(2.1 \%)$ lesions identified in the mandible,

- $4(0.1 \%)$ of them were associated with the apex of the root. Two in the anterior region and 2 in posterior region.
- $52(2 \%)$ were in other locations. Seven were in the anterior region, while 45 in the posterior region).

Figure 3: OPG showing a radio-opacity in posterior mandible

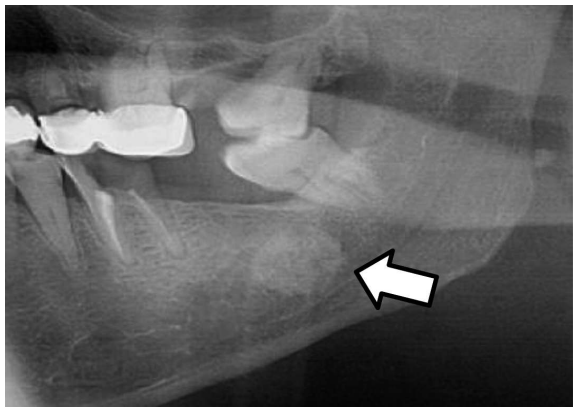

Radiolucencies:

Radiolucent lesions were more prevalent than radiopaque ones. A total of $308(12 \%)$ radiolucencies were identified. Seventy-six (3\%) of the total were present in maxilla, while $202(7.7 \%)$ were in the mandible. In the maxilla:

- $63(2.4 \%)$ associated with the apex of the root. Twentythree $(0.8 \%)$ of these were in anterior jaw, $40(1.5 \%)$ were in the posterior region. Thirteen $(0.5 \%)$ were in other locations, 3 located anteriorly and 10 posteriorly. Two hundred and thirty-two $(8.8 \%)$ were found in the mandible.

- $189(7.2 \%)$ were associated with the apex of the tooth, 45 in the anterior region while 144 in the posterior region.

- There were $43(1.6 \%)$ lesions identified in other locations with $8(0.3 \%)$ of them located anteriorly and $35(1.3 \%)$ posteriorly.

Table 1: Distribution of maxillary and mandibular radiolucencies and radiopacities

\begin{tabular}{|c|c|c|c|c|c|}
\hline \multicolumn{3}{|c|}{ FINDINGS } & \multirow{2}{*}{$\begin{array}{l}\text { ANTERIOR } \\
\text { REGION (n) } \\
23\end{array}$} & \multirow{2}{*}{$\begin{array}{l}\text { POSTERIOR } \\
\text { REGION (n) } \\
40\end{array}$} & \multirow{2}{*}{$\begin{array}{l}\begin{array}{c}\text { TOTAL } \\
\text { n (\%) }\end{array} \\
76(24.7 \%)\end{array}$} \\
\hline RADIOLUCENCIES & \multirow[t]{2}{*}{ MAXILLA } & $\begin{array}{c}\text { ASSOCIATED } \\
\text { WITH TOOTH } \\
\mathrm{n}=68\end{array}$ & & & \\
\hline & & $\begin{array}{c}\text { NOT } \\
\text { ASSOCIATED } \\
\text { WITH TOOTH } \\
n=13\end{array}$ & 3 & 10 & \\
\hline & \multirow[t]{2}{*}{ MANDIBLE } & $\begin{array}{c}\text { ASSOCIATED } \\
\text { WITH TOOTH } \\
\text { n=189 }\end{array}$ & 45 & 144 & \multirow[t]{2}{*}{$232(75.32 \%)$} \\
\hline & & $\begin{array}{c}\text { NOT } \\
\text { ASSOCIATED } \\
\text { WITH TOOTH } \\
n=43\end{array}$ & 8 & 35 & \\
\hline \multirow[t]{4}{*}{ RADIOPACITIES } & \multirow[t]{2}{*}{ MAXILLA } & $\begin{array}{c}\text { ASSOCIATED } \\
\text { WITH TOOTH } \\
\text { n=19 }\end{array}$ & 9 & 10 & \multirow[t]{2}{*}{$38(40.4 \%)$} \\
\hline & & $\begin{array}{c}\text { NOT } \\
\text { ASSOCIATED } \\
\text { WITH TOOTH } \\
n=19\end{array}$ & 3 & 16 & \\
\hline & \multirow[t]{2}{*}{ MANDIBLE } & $\begin{array}{c}\text { ASSOCIATED } \\
\text { WITH TOOTH } \\
n=4\end{array}$ & 2 & 2 & \multirow[t]{2}{*}{$56(59.5 \%)$} \\
\hline & & $\begin{array}{c}\text { NOT } \\
\text { ASSOCIATED } \\
\text { WITH TOOTH } \\
\mathrm{n}=52\end{array}$ & 7 & 45 & \\
\hline
\end{tabular}


Fractures: Fractures were noted on $17(0.6 \%)$ OPGs in the mandible and $3(0.1 \%)$ in the maxilla.

Table 2: Summary of results

\begin{tabular}{|c|c|c|}
\hline ENTITY & ANOMALY & $\begin{array}{c}\text { FREQUENCY } \\
\text { (PERCENTAGE \%) }\end{array}$ \\
\hline \multirow[t]{4}{*}{ MAXILLARY SINUS } & $\begin{array}{l}\text { Pneumatization of the } \\
\text { sinus }\end{array}$ & $312(13.4 \%)$ \\
\hline & Pathologies & 93(4.1\%) \\
\hline & Fractured sinus & $2(0.1 \%)$ \\
\hline & Continuity of the lining & $6(0.3 \%)$ \\
\hline \multirow[t]{3}{*}{ NASAL BONE } & Pathologies & $15(0.6 \%)$ \\
\hline & Deflected nasal septum & $198(8.5 \%)$ \\
\hline & Fracture & $3(0.1 \%)$ \\
\hline \multirow{2}{*}{$\begin{array}{l}\text { ALVEOLAR BONE } \\
\text { LEVEL }\end{array}$} & Generalized bone loss & $798(34.3 \%)$ \\
\hline & Localized bone loss & 60(2.7\%) \\
\hline \multirow{2}{*}{$\begin{array}{l}\text { CONDYLE OF } \\
\text { MANDIBLE }\end{array}$} & Displaced condyles & 916(19.7\%) \\
\hline & Concentric condyles & $3,636(78.2 \%)$ \\
\hline \multirow[t]{2}{*}{ STYLOID PROCESS } & Unilaterally elongated & $21(0.9 \%)$ \\
\hline & Bilaterally elongated & $261(11.2 \%)$ \\
\hline \multirow{2}{*}{$\begin{array}{l}\text { INFERIOR ALVEOLAR } \\
\text { CANAL }\end{array}$} & Pathologies & $10(0.4 \%)$ \\
\hline & Dilation & $20(0.9 \%)$ \\
\hline \multirow[t]{2}{*}{ MAXILLA } & Pathologies & $114(3.9 \%)$ \\
\hline & Fracture & $3(0.1 \%)$ \\
\hline \multirow[t]{2}{*}{ MANDIBLE } & Pathologies & $288(12.3 \%)$ \\
\hline & Fractures & $17(0.7 \%)$ \\
\hline
\end{tabular}

\section{DISCUSSION}

Prior studies have shown variations in sizes and shapes of condyles, sinuses, styloid processes, IAC and mental foramen between populations..$^{4,5-9,11-13}$ Since limited data was available from Pakistan, this study was performed to document the anomalies and pathologies noted on OPGs taken for routine dental care in a single institution. We included entities like sinus dilatation, styloid process elongation, cyst, tumors and fractures of the jaws. This was done by analyzing the OPG images and evaluating the maxillary sinus, condyle of mandible, styloid process, alveolar process, inferior alveolar canal and jaws individually and making record of each radiologic defect.

While OPGs can be used to recognize some maxillary sinus pathologies; such as cysts, pseudo cysts, fractures and others, overlapping structures make definitive assessment difficult, thus favoring reliance on other radiographic techniques. ${ }^{14,15} \mathrm{~A}$ study from Riyadh estimated the prevalence of maxillary sinus abnormalities at $39.4 \% .{ }^{16} \mathrm{~A}$ similar study performed on the Mumbai population but using cone beam computed tomography (CBCT) found the prevalence of maxillary sinus abnormalities to be $59.7 \% .{ }^{17}$ Our study estimated anomalies and abnormalities of the maxillary sinus at $64 \%$. Like the Indian studies, we can expect this number to increase if more precise imaging, like CBCT is used. Sinus pneumatization can be seen in $40-78.7 \%$ of populations according to prior studies. ${ }^{16-19}$ The variations can be attributed to geographical differences.

Nasal fractures can be quite common. They account for $58.6 \%$ of facial fractures, and $40 \%$ of all bone fractures. ${ }^{20}$ This is most likely because of the prominent location of bone. In our estimate we only noted nasal fractures in $0.1 \%$ cases. This low estimate is probably a consequence of acquiring data from routine dental clinics of a single institute. Data from a tertiary healthcare center may yield different results. Deviated nasal septum is also a common finding in OPGs; severe cases can cause difficulty in breathing. We noted a deviated septum in $7.5 \%$ of the OPGs.

Styloid complex consists of styloid process, styloid ligament and stylomandibular ligaments. Elongation of the styloid process can be appreciated on an OPG. ${ }^{21}$ We noted elongations in $12.1 \%$ of our OPGs. Our results are much lower than the reports from Brazil (44\%), Saudi Arabia $(44 \%)$ and Greece $(27 \%) .22-24$ We have attributed this to geographical differences. While elongation of the styloid process is usually asymptomatic, it is linked with Eagle's syndrome. ${ }^{21}$ Due to the absence of clinical information for our OPGs, we were unable to determine how many of our patients were symptomatic.

OPGs are of limited value when evaluating temporomandibular joint (TMJ) disorders. ${ }^{25,26}$ These radiographs are primarily used to assess asymmetries, extensive erosion, tumors and fractures. ${ }^{19}$ Our OPGs showed displacement of the condyle in about $19 \%$ of cases. This included both unilateral and bilateral displacements. Again, due to the absence of clinical information, we were unable to make a definitive assessment of TMJ disorders. Radiolucencies and radiopacities in the jaw can be odontogenic or non-odontogenic. Periapical radiolucencies are a frequent finding on OPGs. We noted them in $9.7 \%$ of our sample. A similar study from England estimated the prevalence of periradicular radiolucencies at $6.8 \% .{ }^{27}$ Other radiolucencies and radiopacities were also noted. Absence of clinical information makes interpretation of this data slightly difficult. A study on the Iranian populations has documented radio-opacities in $2.84 \%$ of their sample. ${ }^{28}$

Alveolar bone levels are important for implants placement, denture prosthesis placement, orthodontic treatment plan, evaluating periodontal health. Alveolar bone loss was frequent in our investigation. About $39 \%$ of our OPGs showed some degree of alveolar bone loss. Our results are corroborated by a Chinese study that showed alveolar bone loss rates at $39.2 \% .{ }^{29}$ In other studies, bone loss in 
about $50 \%$ of the sample has also been reported. ${ }^{30}$

Despite this thorough evaluation of OPGs, our study has its limitations. Absence of clinical information made evaluation of our results difficult. While we tried our best to ensure inclusion of clear images, contrast level of our software could also have influenced our results. We were also unable to account for any magnification errors. For future studies we recommend inclusion of sample from multiple cities across Pakistan and from all types of healthcare facilities; clinics and hospitals.

\section{CONCLUSION}

1. Our results were somewhat unique when compared with studies from other geographical locations.

2. We established baseline statistics about the common anomalies and abnormalities noted in dental radiographs in Pakistan.

3. We believe that this knowledge will help Pakistani dentists familiarize themselves with common anomalies so they can identify abnormalities and provide appropriate patient care.

\section{CONFLICT OF INTEREST}

None to declare

\section{REFERENCES}

1. Vaseemuddin S. Incidental findings on panoramic radiograph: A clinical study. J Adv Med Dent Sci. 2016;4:223-26.

2. Altug HA, Ozkan A. Diagnostic imaging in oral and maxillofacial pathology. Croatia:Intech Europe. 2011;216:26.

3. Magat G, Ozcan S. Evaluation of styloid process morphology and calcification types in both genders with different ages and dental status. J Istanb Univ Fac Dent. 2017;51:29-36.

https://doi.org/10.17096/jiufd.35768

4. Natsis K, Repousi E, Noussios G, Papathanasiou E, Apostolidis S, Piagkou M. The styloid process in a Greek population: An anatomical study with clinical implications. Anat Sci Int. 2014;90:67-74. https://doi.org/10.1007/s12565-014-0232-3

5. Watanabe PC, Dias FC I, JP,, Monteiro SA PF, de Paula FJ TR. Elongated styloid process and atheroma in panoramic radiography and its relationship with systemic osteoporosis and osteopenia. Osteopros Int. 2010;21:831-36.

https://doi.org/10.1007/s00198-009-1022-y

6. Liu T, Xia B, Gu Z. Inferior alveolar canal course: a radiographic study. Clin Oral Implants Res. 2009;20:1212-18.

https://doi.org/10.1111/j.1600-0501.2009.01736.x
7. Sahithi D, Reddy S, Divya Teja DV, Koneru J, Sai Praveen KN, Sruthi R. Reveal the concealed - Morphological variations of the coronoid process, condyle and sigmoid notch in personal identification. Egyptian J Forensic Sci. 2016;6:108-13.

https://doi.org/10.1016/j.ejfs.2015.11.003

8. Yalcin ED, Ararat E. Cone-beam computed tomography study of mandibular condylar morphology. J Craniofac Surg. 2019;30:262124.

https://doi.org/10.1097/SCS.0000000000005699

9. Alrahabi M, Zafar MS. Anatomical variations of mental foramen:A retrospective cross-sectional study. Int J Morpho. 2018;36:1124-29. https://doi.org/10.4067/S0717-95022018000301124

10. Alok A, Singh ID, Panat SR, Singh S, Kishore M, Jha A. Position and symmetry of mental foramen: A radiographic study in Bareilly population. Journal of Indian Academy of Oral Medicine and Radiology. 2017;29:16-9.

https://doi.org/10.4103/jiaomr.JIAOMR_69_16

11. Bakhsh A, Abed H, Hazzazi L, Alzebiani N, Nazer F, Yamany I, et al. Anatomical Variations and Biological Effects of Mental Foramen Position in Population of Saudi Arabia. Dentistry. 2016;6:373. https://doi.org/10.4172/2161-1122.1000373

12. Shahidi S, Zamiri B, Momeni Danaei S, Salehi S, Hamedani S. Evaluation of Anatomic Variations in Maxillary Sinus with the Aid of Cone Beam Computed Tomography (CBCT) in a Population in South of Iran. J Dent (Shiraz). 2016;17:7-15.

13. Selcuk A, Ozcan KM, Akdogan O, Bilal N, Dere H. Variations of maxillary sinus and accompanying anatomical and pathological structures. J Craniofac Surg. 2008;19:159-64.

https://doi.org/10.1097/scs.0b013e3181577b01

14. White SC, Pharoah MJ. Oral radiology : principles and interpretation. 6th ed. ed. United States: St. Louis, Mo. : Mosby Elsevier, c2009.

15. Constantine S, Clark B, Kiermeier A, Anderson PP. Panoramic radiography is of limited value in the evaluation of maxillary sinus disease. Oral Surg Oral Med Oral Pathol Oral Radiol. 2019;127:23746.

https://doi.org/10.1016/j.oooo.2018.10.005

16. Alqahtani S, Alsheraimi A, Alshareef A, Alsaban R, Alqahtani A, Almgran M, et al. Maxillary Sinus Pneumatization Following Extractions in Riyadh, Saudi Arabia: A Cross-sectional Study. Cureus. 2020;12:e6611-e.

https://doi.org/10.7759/cureus.6611

17. Raghav M, Karjodkar FR, Sontakke S, Sansare K. Prevalence of incidental maxillary sinus pathologies in dental patients on cone-beam computed tomographic images. 2014;5:361-65.

https://doi.org/10.4103/0976-237X.137949

18. Tolstunov L, Thai D, Arellano L. Implant-guided volumetric analysis of edentulous maxillary bone with cone-beam computerized tomography scan. Maxillary sinus pneumatization classification. $\mathbf{J}$ 
Asif S/ Babar HB/ Kamal F/ Sohail K/ Kiyani A

Oral Implantol. 2012;38:377-90.

https://doi.org/10.1563/AAID-JOI-D-11-00212

19. Elsayed SA, Alolayan AB, Alahmadi A, Kassim S. Revisited maxillary sinus pneumatization narrative of observation in Al-Madinah Al-Munawwarah, Saudi Arabia: A retrospective cross-sectional study. Saudi Dent J. 2019;31:212-218.

https://doi.org/10.1016/j.sdentj.2018.11.002

20. Kucik CJ, Clenney TL, Phelan J. Management of acute nasal fractures. Am Fam Physician. 2004;70:1315-20.

21. Gokce C, Sisman Y, Ertas ET, Akgunlu F, Ozturk A. Prevalence of styloid process elongation on panoramic radiography in the Turkey population from cappadocia region. Eur J Dent. 2008;2:18-22. https://doi.org/10.1055/s-0039-1697348

22. Vieira EM, Guedes OA, Morais SD, Musis CR, Albuquerque PA, Borges ÁH. Prevalence of Elongated Styloid Process in a Central Brazilian Population. J Clin Diagn Res. 2015;9:ZC90-2.

https://doi.org/10.7860/JCDR/2015/14599.6567

23. AlZarea BK. Prevalence and pattern of the elongated styloid process among geriatric patients in Saudi Arabia. Clin Interv Aging.
Prevalence of radiographic anomalies and abnormalities on panoramic films in the Pakistani population

2017;12:611-17.

https://doi.org/10.2147/CIA.S129818

24. Natsis, K., Repousi, E., Noussios, G. et al. The styloid process in a Greek population: an anatomical study with clinical implications. Anat Sci Int 2015;90:67-74. https://doi.org/10.1007/s12565-014-0232-3

25. Westesson PL. Reliability and validity of imaging diagnosis of temporomandibular joint disorder. Adv Dent Res. 1993;7:137-51. https://doi.org/10.1177/08959374930070020401

26. Crow HC, Parks E, Campbell JH, Stucki DS, Daggy J. The utility of panoramic radiography in temporomandibular joint assessment. Dentomaxillofac Radiol. 2005;34:91-5. https://doi.org/10.1259/dmfr/24863557

27. Richardson PS. Panoramic radiographic screening: a risk-benefit analysis. Prim Dent Care. 1997;4:71-7.

28. Naser AZ, Roshanzamir N. Prevalence of idiopathic osteosclerosis in an Iranian population. Indian J Dent Res. 2016;27:544-46. https://doi.org/10.4103/0970-9290.195679 